\title{
Effectiveness of a program to improve antibiotic use in children hospitalized in a children's tertiary care facility in Argentina
}

\author{
Silvina Ruvinsky, M.D., ${ }^{a}$ Andrea Mónaco, M.D., ${ }^{a}$ Guadalupe Pérez, M.D., ${ }^{a}$ \\ Moira Taicz, M.D. ${ }^{a}$ Laura Inda, M.D.,${ }^{a}$ Carolina Epelbaum, M.D., ${ }^{a}$ \\ Ivana Kijko, M.D., ${ }^{b}$ Patricia Constanzo, M.D. ${ }^{b}$ and Rosa Bologna, M.D. ${ }^{a}$
}

\begin{abstract}
Introduction. Inadequate antibiotic use is associated with an increased emergence of resistant microorganisms, higher morbidity and mortality rates, and an impact on public health. Objective. To assess the effectiveness of a program aimed at improving the use of antimicrobials in patients hospitalized at Hospital Garrahan.

Material andMethods.Prospective, longitudinal, before and after study with no control group. Study period: From November 1 ${ }^{\text {st }}, 2010$ to June $30^{\text {th }}, 2011$. Patients receiving parenteral antibiotics were included. Newborn infants, burned patients and those receiving prophylactic antibiotics were excluded. The periods before and after implementing discussion and monitoring workshops for antibiotic prescription and distributing treatment guidelines were compared. An univariate analysis and a multiple logistic regression study were performed (STATA 8.0).
\end{abstract}

Results. In thepre-intervention period,376 patients were included; of them, $35.6 \%$ had received inadequate treatment. The multiple regression analysis showed that the endpoints for inadequate antibiotic use were acute lower respiratory tract infection (OR:3.80;95\% CI: 1.35-3.26; $p=0.04$ ), fever without a source in hospitalized patients (OR: 5.55; 95\% CI: $2.43-12.6 ; p<0.01$ ), and febrile neutropenia (OR: $0.29 ; 95 \%$ CI: $0.10-0.7 ; p<0.01$ ).

a. Epidemiology and Infectious Disease Department.

b. Pharmacy Division.

Children's Hospital

"Prof. Dr. Juan P.

Garrahan."

\section{Funding:}

This study was conducted in the context of a research grant awarded by Fundación del Hospital de Pediatría "Prof. Dr. Juan P. Garrahan."

\section{E-mail Address:}

Silvina Ruvinsky, M.D.: sruvinsky@hotmail.com

Conflict of Interest:

None.

Received: 9-18-2012 Accepted: 10-25-2013

\section{INTRODUCTION}

The emergence of multi-drug resistant microorganisms and its impact on the higher morbidity and mortality rates in hospitalized patients have been associated with an indiscriminate use of antimicrobials and increased health care-related costs. ${ }^{1}$ Different strategies for reducing inadequate antibiotic use have been evaluated, but measures aimed at restricting specific agents (broad spectrum or expensive antibiotics) have demonstrated a lower impact. However, training programs for members of treating teams, review of indications by more experienced health care professionals, and developing guidelines adapted to local challenges have been reported as effective, long-term strategies. Prior studies have shown that the effectiveness of each intervention implemented separately is limited; adherence to each of these strategies is usually voluntary and cannot be sustained over time without an active program to support them..$^{2-4}$

Appropriate antibiotic use policies have been validated in the adult population, but less information is available regarding their impact on pediatric patients. ${ }^{5}$

The objective of this study was to analyze the effectiveness of a program to improve the proportion of adequate antibiotic prescriptions and enhance antimicrobial use in children hospitalized in a tertiary care facility.

The study hypothesis was that the implementation of a training program for the judicious use of antibiotics targeted at the members of treating health care teams would optimize antibiotic prescription in hospitalized children.

\section{POPULATION AND METHODS}

Prospective, longitudinal, preand post-intervention study with no control group. An analysis of the 
previous situation, the intervention, and the posterior evaluation was performed. Patients included were 1 month to 16 years old, receiving parenteral antibiotic therapy and admitted into the Emergency Department, the Intensive Care Unit and Inpatient Wards. Patients receiving antimicrobial agents as surgical prophylaxis, newborn infants and burned patients were excluded. The study was done at the Children's Hospital "Prof. Dr. Juan P. Garrahan," a tertiary care, teaching hospital that is referred patients with complex conditions from across the country. The study was approved by the Ethics Committee. Protocol No 625.

Study period: From July $1^{\text {st }}, 2010$ to June $30^{\text {th }}, 2011$. The pre-intervention period, the intervention and the post-intervention period lasted 4 months each. Patients were randomly selected using the hospital's database of hospitalized patients receiving parenteral antibiotics issued by the pharmacy unit.

Patient data were recorded throughout their hospitalization to assess adequate antibiotic use. Demographic characteristics (sex, age, weight, date of admission, date of discharge, underlying disease, initial diagnosis and diagnosis upon discharge), prior invasive procedures, prescribed antibiotics: type of antibiotic, frequency, administration route and duration. Additional data included the presence of a clinical source of infection, clinical exam findings, and additional test results (X-rays and microbiological isolates).

Clinical data were obtained from medical records and the information system of patients hospitalized in this facility. Age was stated in months. The diagnosis of infection was based on the code of each condition. The antibiotic (dose and dosing interval) prescribed by the attending physician was recorded. An empiric treatment was defined as one started within 72 hours of diagnosis, before obtaining culture results. A definite treatment was defined as one continued 72 hours after diagnosis or modified as per microbiological confirmation.

Treatment was considered adequate when it included the antimicrobials suggested in the hospital guidelines or recommendations according to the microbiological diagnosis, taking into account the following: condition, dose, interval and duration; if otherwise, treatment was considered inadequate. Infections leading to the initiation of an antibiotic therapy were considered community-acquired when the diagnosis was made within 48 hours of admission, and were considered hospital-acquired when the infection was not present at the time of patient admission and developed more than 48 hours after the hospitalization.

Adequacy analysis: Two pediatricians specialized in infectious diseases performed the adequacy analysis as independent observers; any discrepancy was resolved by an external specialist in infectious diseases. Patients were classified as category I if they required antibiotics but these were inadequately selected (broader or narrower spectrum, different dose, duration or administration route than required), and as category II if patients did not require an antibiotic indication. Adequacy was defined based on the Hospital Garrahan guidelines in force. ${ }^{6-8}$

\section{Interventions conducted during the program}

A report was developed based on results obtained in the initial stage, which was then disseminated to inform health care team members about the program. In the beginning, meetings and discussions were held with the different hospitalization area coordinators. Based on collected data, discussion workshops were designed so as to discuss conflicting clinical situations observed when choosing an empiric antibiotic treatment: fever in a patient admitted to the general hospitalization unit or the ICU, fever during the postoperative period, antibiotic use for pneumonia and acute lower respiratory tract infections (ALRTIs) in a hospitalized patient, and recommendations for the use of ceftriaxone in a hospitalized patient.

Twenty workshops were conducted where medical assistants, fellow residents, pharmacists and infectious disease specialists from the different hospitalization areas had an active participation. The most commonly observed inadequate interventions at the time of establishing the antibiotic prescription and valid recommendations were discussed. ${ }^{6-8}$

Interactive workshops allowed to obtain more information on conflicting situations regarding antibiotic use overlooked during the initial registration. Management algorithms for skin and soft tissue infections (SSTIs) and antibiotic indications for ALRTI were developed and disseminated, and extensions of surgical prophylaxis were reviewed.

Statistical analysis: The mean, median and interquartile range (IQR) were estimated for continuous outcome measures. These were analyzed using the $t$ test or Wilcoxon test, as applicable. Categorical outcome measures were 
analyzed using the Chi-square or Fisher's test, depending on the sample size. Univariate and logistic regression analyses were performed. After reviewing each independent outcome measure separately (age, sex, underlying disease, infection type, initial clinical source of infection, microbiological isolate) and comparing them to the categorical dependent outcome measure (adequate antibiotic use), the best outcome measures were selected taking into account confounding factors and possible interactions ("forward" manual selection). The model appropriateness (Romer Lemershow) was then examined. A $p$ value $<0.05$ was considered statistically significant. The STATA 8.0 software was used for the analysis.

Sample size: Considering a 95\% confidence interval with a value of 0.30 proposed for the $p$ parameter (proportion of inadequate antibiotic use), a 50\% reduction, and an estimated loss of probably less than $20 \%$, it was estimated that the sample would require 200 patients for the initial assessment and 200 patients for the postintervention assessment.

\section{RESULTS \\ Pre-intervention period}

Three hundred and seventy six patients receiving parenteral antibiotics were included. The sample characteristics are detailed in Table 1. Treatment was considered inadequate in 35.6\% $(n=134)$ of them. Reasons for inadequate use were classified as category I in $54.5 \%(n=73)$ of the cases and as category II in $45.52 \%(n=61)$ of the cases.

In group I, $61 \%$ of patients $(n=50)$ received a broader spectrum antibiotic, while $4.9 \%(n=4)$, a narrower spectrum antibiotic. Treatment lasted longer than recommended in $29.3 \%(n=24)$ of patients. The dose was incorrect in $2 \%(n=2)$ of patients, and the route of administration used was the wrong one in $2 \%(n=2)$.

A total of 529 antibiotic prescriptions were made for 376 evaluated patients. When analyzing the type of antibiotics prescribed, ceftriaxone and ampicillin-sulbactam were the most commonly used inadequately (Table 2).

Clinical situations leading to the inadequate use are detailed in Table 3. The most common reasons for inadequate use were ceftriaxone

TABLE 1. General characteristics of patients included in the pre-intervention and post-intervention periods

\begin{tabular}{|c|c|c|c|c|c|c|c|c|}
\hline \multirow[t]{2}{*}{ Outcome measure } & \multicolumn{3}{|c|}{ Pre-intervention } & \multicolumn{5}{|c|}{ Post-intervention } \\
\hline & $\begin{array}{c}\text { Total } \\
(\mathrm{n}=376)\end{array}$ & $\begin{array}{c}\text { Inadequate } \\
(\mathrm{n}=134)\end{array}$ & $\begin{array}{c}\text { OR } \\
\text { (IC } 95 \%)\end{array}$ & $\mathbf{P}$ & $\begin{array}{c}\text { Total } \\
(\mathrm{n}=357)\end{array}$ & $\begin{array}{c}\text { Inadequate } \\
\quad(n=77)\end{array}$ & $\begin{array}{c}\text { OR } \\
(\mathrm{CI} 95 \%)\end{array}$ & $\mathbf{P}^{*}$ \\
\hline $\begin{array}{l}\begin{array}{l}\text { Age in months } \\
\text { (median, } \mathrm{IQR}^{* *} \text { ) }\end{array} \\
\end{array}$ & $\begin{array}{c}50 \\
(14.5-127) \\
\end{array}$ & $\begin{array}{c}46 \\
(15-143) \\
\end{array}$ & & $0.43\left(^{*}\right)$ & $\begin{array}{c}50 \\
(13-124) \\
\end{array}$ & $\begin{array}{c}26 \\
(9-122) \\
\end{array}$ & & $0.08\left(^{*}\right)$ \\
\hline Male gender (\%) & $218(57.98 \%)$ & $77(57.46)$ & $\begin{array}{c}0.96 \\
(0.63-1.48)\end{array}$ & 0.88 & $\begin{array}{c}137 \\
(38.3)\end{array}$ & $\begin{array}{c}29 \\
(37.26)\end{array}$ & $\begin{array}{c}0.96 \\
(0.55-1.67)\end{array}$ & 0.88 \\
\hline $\begin{array}{l}\text { Underlying } \\
\text { disease } * *(\%) \\
\text { Hematooncological } \\
\text { disease } \\
\text { Neurological disease } \\
(*) \text { Others (cardiovascular } \\
\text { disease Transplanted } \\
\text { for biliary atresia/ GI } \\
\text { malformations, Uropathy) }\end{array}$ & $\begin{array}{c}282 \\
(75 \%) \\
45 \% \\
10 \%\end{array}$ & $\begin{array}{c}99 \\
(73.88)\end{array}$ & $\begin{array}{c}0.91 \\
(0.55-1.52)\end{array}$ & 0.70 & $\begin{array}{c}118 \\
(42.14) \\
\\
41 \% \\
15 \%\end{array}$ & $\begin{array}{c}43 \\
(55.84)\end{array}$ & $\begin{array}{c}3.46 \\
(1.99-6)\end{array}$ & $<0.01$ \\
\hline $\begin{array}{l}\text { Previous invasive } \\
\text { procedure }(\%)\end{array}$ & $\begin{array}{c}166 \\
(44.15) \\
\end{array}$ & $\begin{array}{c}57 \\
(42.54) \\
\end{array}$ & $\begin{array}{c}0.9 \\
(0.58-1.41) \\
\end{array}$ & 0.64 & $\begin{array}{c}149 \\
(41.85) \\
\end{array}$ & $\begin{array}{c}31 \\
(40.79) \\
\end{array}$ & $\begin{array}{c}0.93 \\
(0.54-1.59) \\
\end{array}$ & 0.76 \\
\hline $\begin{array}{l}\text { Immunosuppressive } \\
\text { treatment }\end{array}$ & $\begin{array}{c}133 \\
(35.5 \%)\end{array}$ & & & & $\begin{array}{c}94 \\
(26.3)\end{array}$ & & & \\
\hline $\begin{array}{l}\text { Initial clinical source } \\
\text { of infection }(\%)\end{array}$ & $\begin{array}{c}304 \\
(80.85) \\
\end{array}$ & $\begin{array}{l}86 \\
(64) \\
\end{array}$ & \begin{tabular}{|c|}
0.20 \\
$(0.11-0.35)$ \\
\end{tabular} & $<0.0001$ & $\begin{array}{c}271 \\
(76.55) \\
\end{array}$ & $\begin{array}{l}57 \\
(75) \\
\end{array}$ & $\begin{array}{c}0.88 \\
(0.48-1.64) \\
\end{array}$ & 0.77 \\
\hline $\begin{array}{l}\text { Microbiological } \\
\text { confirmation (\%) }\end{array}$ & $\begin{array}{c}153 \\
(40.69)\end{array}$ & $\begin{array}{c}39 \\
(29.10)\end{array}$ & $\begin{array}{c}0.46 \\
(0.29-0.74)\end{array}$ & 0.0006 & $\begin{array}{c}166 \\
(47.03)\end{array}$ & $\begin{array}{c}41 \\
(53.95)\end{array}$ & $\begin{array}{c}1.41 \\
(0.83-2.42)\end{array}$ & 0.18 \\
\hline
\end{tabular}

$\left.{ }^{*}\right)$ Chi-square test $\left(\chi^{2}\right)$ for categorical outcome measures or Wilcoxon test for continuous outcome measures.

${ }^{(* *}$ IQR: interquartile range. $\left.{ }^{* * *}\right)$ Some patients had more than one underlying concurrent disease. 
prescribed for uncomplicated pneumonia (due to a broader spectrum than required) and for bronchiolitis without sepsis or radiological signs indicative of pneumonia. Most of the patients who developed fever during hospitalization $(n=25)$ were postoperative or children with an underlying disease (without immune compromise) who were receiving parenteral antibiotics, although no clinical source of infection had been identified and cultures were negative. Patients with no signs of infection who received antibiotics $(n=17)$ were postoperative (mostly traumatologic, urological or colon surgeries), and their prophylaxis was extended beyond what was required and so it was regarded as treatment and included in the analysis.

When comparing each independent outcome measure with the dependent outcome measure "inadequate antibiotic use," statistically significant risk factors were the presence of fever without a source in a hospitalized patient and the presence of ALRTI, and protection factors were having microbiological records, the presence of an initial clinical source of infection, and febrile neutropenia (Tables 1, 2 and 3).

The multiple regression analysis showed that predictor endpoints for inadequate antibiotic use were ALRTI diagnosis, OR: 3.80 (1.34-3.27), $p=0.04$; presence of fever without a source in hospitalized patients, OR: 5.5 (95\% CI: 2.42-12.6), $p<0.01$; and febrile neutropenia, OR: 0.29 (95\% CI: 0.10-0.7), $p<0.01$.

\section{Post-intervention period}

Three hundred and fifty seven patients were included. General characteristics of the population were similar to those in the preintervention period (Table 1). Parenteral antibiotic treatment was inadequate in $21.57 \%(n=77)$; a statistically significant reduction was observed compared to the previous period (OR: 0.50 [0.35-0.70], $p<0.01)$. Regarding the reasons for inadequate use, $94 \%$ were classified as category I, while $6 \%$ corresponded to category II.

In most cases, a broader spectrum antibiotic had been selected $(n=67)$, and the wrong route of administration was used in 2 patients (receiving parenteral treatment when it should have been oral). The rest of the patients $(n=8)$ did not require antibiotics (category II).

A total of 684 antibiotic prescriptions were recorded; 153 were inadequate (Table 4). In spite of the interventions performed, ceftriaxone continued to be the antibiotic most inadequately used (Table 4).

Unlike the pre-intervention period, an adequate antibiotic use for ALRTIs was significantly higher (Table 3).

The number of patients with SSTIs increased from the pre-intervention period, probably because the registry started during the SpringSummer months. An improvement was observed in the antibiotic prescriptions for these infections compared to the previous period (clindamycin treatment instead of ceftriaxone-combined treatment, as recorded in the first half of the study period) (Table 3).

There was a statistically significant reduction in the number of inadequate prescriptions for hospitalized patients who developed fever without a clinical source of infection and in the

TABLE 2. Distribution of 529 antibiotic prescriptions and adequacy analysis in 376 evaluated patients (pre-intervention period)

\begin{tabular}{lcccc}
\hline Antibiótico prescripto & Total $(\mathbf{n}=\mathbf{5 2 9})$ & Inadequate $(\mathbf{n}=\mathbf{1 7 4})$ & OR (95\% CI) & P (*) \\
\hline Ceftriaxone & 126 & 56 & $1.76(1.11-2.81)$ & 0.015 \\
Vancomycin & 91 & 29 & $0.80(0.47-1.36)$ & 0.46 \\
Carbapenems* & 101 & 28 & $0.61(0.36-1.04)$ & 0.068 \\
Ampicillin-sulbactam & 34 & 20 & $3.21(1.48-6.98)$ & 0.001 \\
Cefalotin & 22 & 10 & $1.55(0.60-3.96)$ & 0.44 \\
Piperacillin-tazobactam & 28 & 9 & $0.85(0.34-2.04)$ & 0.84 \\
Ceftazidime & 58 & 17 & $0.71(0.37-1.36)$ & 0.34 \\
Colistin & 11 & 4 & - & - \\
Ornidazole & 16 & 2 & - & - \\
Clindamycin & 32 & 0 & - & \\
Ciprofloxacin & 5 & 0 & 0 & - \\
Ampicillin & 5 & 0 & & \\
\hline
\end{tabular}

* Chi-square test $\left(\mathrm{X}_{2}\right)$ for categorical outcome measures. 
number of extended postoperative prophylaxis compared to the previous period (Table 3).

The multivariate analysis of the postintervention period showed that predictor endpoints for inadequate antibiotic use were: SSTI, OR: 0.33 (95\% CI: 0.13-0.93), $p=0.035$, and presence of febrile neutropenia, OR: 0.48 (95\% CI: 0.22-0.94), $p=0.04$.

\section{DISCUSSION}

Inadequate antibiotic use is a challenge for public health. Programs to improve antibiotic prescription constitute the cornerstone to prevent the development of resistant microorganisms, reduce morbidity and mortality, save costs, and enhance the quality of care provided to hospitalized children. ${ }^{9-12}$

TABLE 3. Distribution of inadequate antibiotic use by infection site, pre-and post-intervention

\begin{tabular}{|c|c|c|c|c|c|c|}
\hline \multirow{3}{*}{ Infection site } & \multicolumn{4}{|c|}{ Antibiotic use } & \multirow{3}{*}{ OR $(95 \% \mathrm{CI})$} & \multirow{3}{*}{$\mathbf{P}^{*}$} \\
\hline & \multicolumn{2}{|c|}{ Pre-intervention } & \multicolumn{2}{|c|}{ Post-intervention } & & \\
\hline & Adequate (n) & Inadequate (n) & Adequate (n) & Inadequate (n) & & \\
\hline Fever without a clinical source & 11 & 25 & 12 & 7 & $0.2(0.11-0.69)$ & $<0.01$ \\
\hline Febrile neutropenia & 67 & 6 & 55 & 7 & $\mathrm{NS}^{* *}$ & \\
\hline Skin and soft tissue infections & 18 & 10 & 46 & 5 & NS & \\
\hline ENT infection & 3 & 0 & 3 & 3 & NS & \\
\hline ALRTI $^{* * *}$ & 59 & 52 & 57 & 17 & $0.31(0.17-0.57)$ & $<0.01$ \\
\hline GI/intra-abdominal & 19 & 7 & 23 & 10 & NS & \\
\hline Urinary tract infection & 9 & 3 & 12 & 1 & NS & \\
\hline CNS infection & 17 & 1 & 16 & 7 & NS & \\
\hline Cardiovascular infection & 5 & 3 & 5 & 2 & NS & \\
\hline Osteoarticular infection & 8 & 4 & 15 & 6 & NS & \\
\hline Bacteremia/sepsis & 19 & 6 & 22 & 4 & NS & \\
\hline Surgical site infection & 7 & 0 & 6 & 3 & NS & \\
\hline Extended surgical prophylaxis $* * * *$ & 0 & 17 & 0 & 4 & $0.24(0.07-0.76)$ & 0.011 \\
\hline Total & 242 & 134 & 280 & 77 & $0.50(0.35-0.70)$ & $<0.01$ \\
\hline
\end{tabular}

* Chi-square test $\left(\chi^{2}\right)$ for categorical outcome measures. ${ }^{* *}$ NS: not significant.

*** ALRTI: acute lower respiratory tract infection, including pneumonia and bronchiolitis.

**** Urological, traumatologic and colon surgeries.

TABLE 4. Distribution of antibiotic prescriptions and adequacy analysis in 357 assessed patients (post-intervention period)

\begin{tabular}{lcccc}
\hline Prescribed antibiotic & Total $\mathbf{( n = 6 8 4 )}$ & Inadequate $(\mathbf{n}=\mathbf{1 5 3})$ & OR (95\% CI) & $\mathbf{P}^{*}$ \\
\hline Ceftriaxone & 135 & 44 & $2.77(1.60-4.79)$ & 0.0001 \\
Vancomycin & 137 & 35 & $1.45(0.85-2.50)$ & 0.15 \\
Carbapenems & 109 & 24 & $1.04(0.58-1.85)$ & 0.89 \\
Ampicillin-sulbactam & 31 & 5 & $0.68(0.22-1.95)$ & 0.58 \\
Cefalotin & 22 & 3 & $0.56(0.13-2)$ & 0.43 \\
Piperacillin-tazobactam & 56 & 10 & $0.76(0.34-1.66)$ & 0.57 \\
Ceftazidime & 45 & 10 & $1.04(0.46-2.33)$ & 0.93 \\
Colistin & 16 & 2 & $0.51(0.08-2.41)$ & 0.53 \\
Ornidazole & 13 & 4 & $1.67(0.41-6)$ & 0.48 \\
Clindamycin & 76 & 13 & $0.70(0.34-1.41)$ & 0.28 \\
Ciprofloxacin & 13 & 2 & $0.68(0.10-3.33)$ & 1 \\
Ampicillin & 31 & 1 & - & - \\
\hline
\end{tabular}

\footnotetext{
* Chi-square test $\left(\chi^{2}\right)$ for categorical outcome measures.
} 
The profile of patients included in this study, most of whom with chronic conditions, immune compromise or other underlying disorders, corresponds to the usual population of patients seen at Hospital Garrahan, a national referral facility for patients with complex conditions. ${ }^{13}$

The frequency of inadequate antibiotic use ranges from $20 \%$ to $50 \%^{14-17}$ similar to what has been observed in our series.

Ceftriaxone is one of the antibiotics commonly used inadequately in hospitalized patients. Its use to treat pneumonia instead of ampicillin ${ }^{18-21}$ in patients with other ALRTIs (bronchiolitis, pertussis), and the unnecessary extension of parenteral treatment are examples of inadequate use also observed in other facilities. ${ }^{22,23}$

The inadequate use of ampicillin-sulbactam was mostly related to extended antibiotic prophylaxis and its indication for fever in postoperative patients with no clinical source of infection. Extended surgical prophylaxes, regarded as treatments in this study, constituted a rather major inadequate antibiotic use in the pre-intervention period. The reason for extending prophylaxis was mostly the false perception that extended antibiotic use might prevent an infection in the surgical site for highly aggressive procedures or in the presence of long-term catheters or tubes.

Physicians' decision regarding antimicrobial indication is influenced by different factors with varying levels of complexity, such as training in the use of antimicrobial therapy, deficient or inexistent continuous education programs, lack of quality controls on patients receiving antimicrobials.

In turn, sometimes there is a gap between the best available evidence and clinical practice. Based on bibliographic evidence ${ }^{24-27}$ the intervention implemented in this hospital was of an educational nature.

This strategy was complemented with the daily monitoring of medical indications by members of the Hospital's Infectious Disease and Pharmacy Units.

Newman, et al. observed an increase in the prescription of ampicillin and a reduction in the use of ceftriaxone in children hospitalized due to acute community-acquired pneumonia following the implementation of a clinical practice recommendation. ${ }^{28}$

Bantar, et al. observed a reduction in the use of carbapenem and ceftriaxone due to the implementation of an education program and control of antibiotic prescriptions. ${ }^{15}$
The World Health Organization (WHO) recommends to periodically update treatment and prophylaxis guidelines, to monitor antibiotic use (quantity and administration modality), and continuous surveillance of antimicrobial sensitivity. It has been recognized that it is necessary to analyze data and disseminate reports on the health care process, together with a continuous assessment of antimicrobial use during the study. Establishing continuous education programs based on monitoring is a fundamental approach to train members of health care teams on the use of antimicrobials. ${ }^{29,5}$

These modalities can be complemented by educational interventions, both incidental and continuous, and by disseminating clinical practice guidelines.

The recommendations for antimicrobial use should be updated, adapted to local epidemiology, and available for all members of health care teams. ${ }^{30,31}$ A different strategy proposed entails shortening antibiotic regimens in hospitalized patients. ${ }^{32,33}$

Following this intervention, a reduction in the indication of empiric ceftriaxone for community-acquired respiratory conditions, adequate duration of surgical prophylaxis, and an improvement in antibiotic use for patients with fever without a clinical source of infection, such as SSTIs, were observed. A better antibiotic prescription for patients with SSTIs is probable related to the dissemination of hospital's treatment recommendations for communityacquired methicillin-resistant Staphylococcus aureus (MRSA). ${ }^{6}$

Febrile neutropenia was found to be a predictor of adequate use, probably because the hospital's management guidelines for fever in hematooncological patients are clear and have been widely disseminated and accepted. ${ }^{7}$

Although viral infections are more prevalent in children, antibiotics are the most commonly used drugs in pediatrics.

An increased availability of rapid diagnostic methods to determine if an infection is of viral or bacterial nature ${ }^{12,31,34,35}$ would help to reduce the inadequate use of empiric antibiotics and establish an adequate therapy earlier.

Undoubtedly, microbiological confirmation and the identification of the clinical source of infection provide greater safety and certainty in relation to antibiotic prescription.

The main weaknesses of this study are the absence of a control group and the seasonal difference observed in the initial period versus the 
final period. The seasonal variation had an impact on the reduction of viral ALRTIs in the second part compared to the first one, thus making it difficult to assess antimicrobial treatment modifications in this specific group of patients. The educational intervention implemented in the hospital implies a modification in physicians' behavior, and it is likely it will require more time to make an objective assessment of its effects.

Clinical conditions leading to inadequate antibiotic use are usually and systematically repeated. As observed in this study, it is essential to identify those situations so as to implement a program targeted at issues detected at a local level.

\section{CONCLUSION}

The program reduced the proportion of inadequate antibiotic use from $35.6 \%$ to $21.6 \%$. The intervention based on an educational program allowed to enhance antimicrobial use in this hospital.

\section{REFERENCES}

1. Mora Y, Avila-Aguero ML, Umana MA, Jimenez AL, et al. Epidemiological observation of the judicious use of antibioics in a pediatric teaching hospital. Int J Infect Dis 2002;6:74-7.

2. Lee J, Carlson J, Chamberlain M, et al. A team approach to hospital formulary replacement. Diagn Microbiol Infect Dis 1995;22:239-42.

3. Knox K, Holmes A. Regulation of antimicrobial prescribing practices-a strategy forcontrollingnosocomial antimicrobial resistance. Int J Infect Dis 2002;6(suppl 1):S8-13.

4. Gross R, Morgan A, Kinky D, et al. Impact of a hospitalbased antimicrobial management program on clinical and economic outcomes. Clin Infect Dis 2001;33:289-95.

5. Dellit TH, Owens RC, McGowan JE Jr, Gerding DN, et al. Infectious Diseases Society of America and the Society for Healthcare Epidemiology of America guidelines for developing an institutional program to enhance antimicrobial stewardship. Clin Infect Dis 2007;44(2):159-77.

6. Rosanova MT, Berberian G, Ruvinsky S, Sarkis C, et al. Infecciones por Staphylococcus aureus meticilinorresistente de la comunidad. Tratamiento basado en la evidencia. Medicina Infantil 2011;28(1):76-8.

7. Paganini H. Enfoque clínico y tratamiento de los niños con neutropenia y fiebre. Arch Argent Pediatr 2007;105(3):225-35.

8. Paganini H y Ruvinsky S. Enfoque diagnóstico y terapéutico del niño internado con fiebre. En: Medicina Interna Pediátrica. Buenos Aires: Editorial Fundación Garrahan; 2005.Págs.109-40.

9. Septimus EJ, Owens RC. Need and potential of antimicrobial stewardship in community hospitals. Clin Infect Dis 2011;53(S1):S8-S14.

10. Kollef MH, Golan Y, Scott TM, Shorr AF, et al. Appraising contemporary strategies to combat multidrug resistant gram-negative bacterial infections-proceedings and data from the gram-negative resistance summmit. Clin Infect Dis 2011;53(S2):S33-S55.

11. Bartlett JG. A Call to Arms: The Imperative for antimicrobial stewardship. Clin Infect Dis 2011;53(S1):S4-S7.

12. Pulcini C, Bush K, Craig WA, Frimodt-Meller N, et al. and
theESCMIDStudy Group for AntibioticPolicies. Forgotten antibiotics: an inventory in Europe, the United States, Canada and Australia. Clin Infect Dis 2012;54(2):268-74.

13. Hospital de Pediatría Dr. Juan P. Garrahan: Indicadores de producción. [Accessed on: August 6, 2012]. Available at: http:/ / www.garrahan.org.ar.

14. PotockiM,GoetteJ,Szucs TD, Nadal D. Prospectivesurvey of antibiotic utilization in pediatric hospitalized patients to identify targets for improvement of prescription. Infection 2003;31:398-403.

15. Bantar C, Sartori B, Vesco E, Heft C, et al. A hospital wide intervention program to optimize the quality of antibiotic use: impact on prescribing practice, antibiotic consumption, cost savings, and bacterial resistance. Clin Infect Dis 2003;37:180-6.

16. Gross R, Morgan A, Kinky D, Weiner M, et al. Impact of a hospital- based antimicrobial management program on clinical and economic outcomes. Clin Infect Dis 2001;33:28995.

17. Grohskopf LA, Huskins WC,Sinkowitz-Cochran RL, Levine GL, et al. Pediatric Prevention Network. Use of antimicrobial agents in United States neonatal and pediatric intensive care patients. Pediatr Infect Dis J 2005;24:766-73.

18. Bradley JS, Byington CL, Shah SS, Alverson B, et al. The management of community-acquired pneumonia in infants and children older than 3 months of age: clinical practice guidelines by the Pediatric Infectious Diseases Society and the Infectious Diseases Society of America. Clin Infect Dis 2011;53(7):e25-e76.

19. Bradley JS. Highlights from clinical practice guidelines by the Pediatric Infectious Diseases Society (PIDS) and the Infectious Diseases Society of America (IDSA) for the management of community-acquired pneumonia (CAP) in infants and children older than 3 months of age. Infect Dis Clin Pract 2012;20:63-5.

20. Kumar P, Mac Kean MC. Evidence based paediatrics: review of BTS guidelines for the management of community acquired pneumonia in children. J Infect 2004;48(2):134-8.

21. Consenso de la Sociedad Latinoamericana de Infectología Pediátrica sobre Neumonía Adquirida en la Comunidad. (Coordinador: Ruvinsky R.) Rev Enfer Infecc Pediatr (México) 2010;24 (94):1-23.

22. Oosterheert JJ, Bonten MJ, Schneider MM, Buskens E, et al. Effectiveness of early switch from intravenous to oral antimicrobials in severe community acquired pneumonia: multicentre randomised trial. BMJ 2006;333:1193-5.

23. Peltola H, Vuori-Holopainen E, Kallio MJT; SE-TU Study Group. Successful shortening from seven to four days of parenteral beta-lactam treatment for common childhood infections: a prospective and randomized study. Int J Infect Dis 2001;5:3-8.

24. Arnold FW, McDonald LC, Smith RS, Newman D, et al. Improving antimicrobial use in the hospital setting by providing usage feedback to prescribing physicians. Infect Control Hosp Epidemiol 2006;27(4):378-82.

25. Mol PG, Wieringa JE, NannanPanday PV, Gans RO, et al. Improving compliance with hospital antibiotic guidelines: a time-series intervention analysis. J Antimicrob Chemother 2005;55:550-7.

26. Camins BC, King MD, Jane B, Wells JB, et al. Impact of an antimicrobial utilization program on antimicrobial use at a large teaching hospital: a randomized controlled trial. Infect Control Hosp Epidemiol 2009;30:931-8.

27. Philmon C, Smith T, Williamson S, Goodman E. Controlling use of antimicrobials in a community teaching hospital. Infect Control Hosp Epidemiol 2006;27:239-44.

28. Newman R, Hedican E, Herigon J, Williams D, et al. Impact of a guideline on management of children hospital- 
ized with community-acquired pneumonia. Pediatrics 2012; 129:e597-e604.

29. Sáez-Llorens X, Castrejón de Wong MM, Castaño E, De Suman O, et al. Impact of an antibiotic restriction policy on hospital expenditures and bacterial susceptibilities: a lesson from a pediatric institution in a developing country. Pediatr Infect Dis J 2000;19:200-6.

30. Deuster S, Roten I, Muehlebach S. Implementation of treatment guidelines to support judicious use of antibiotic therapy. J Clin Pharm Ther 2010;35(1):71-8.

31. Jamtvedt G, Young JM, Kristoffersen DT, O'Brien MA, et al. Audit and feedback: effects on professional practice and health care outcomes. Cochrane Database Syst Rev 2006;(2):CD000259.

32. Hayashi $Y$, Paterson D. Strategies for reduction in duration of antibiotic use in hospitalized patients. Clin Infect Dis 2011;52(10):1232-124.

33. Bratzler DW, Houck PM. Surgical Infection Prevention Guidelines Writers Workgroup; American Academy of Orthopaedic Surgeons; American Association of Criti- cal Care Nurses; American Association of Nurse Anesthetists; American College of Surgeons; American College of Osteopathic Surgeons; American Geriatrics Society; American Society of Anesthesiologists; American Society of Colon and Rectal Surgeons; American Society of HealthSystem Pharmacists; American Society of PeriAnesthesia Nurses; Ascension Health; Association of periOperative Registered Nurses; Association for Professionals in Infection Control and Epidemiology; Infectious Diseases Society of America; Medical Letter; Premier; Society for Healthcare Epidemiology of America; Society of Thoracic Surgeons; Surgical Infection Society.Antimicrobial prophylaxis for surgery: an advisory statement from the National Surgical Infection Prevention Project. Clin Infect Dis 2004;38:1706-15.

34. Rice LB. Rapid diagnostics and appropriate antibiotic use. Clin Infect Dis 2011;52(S4):S357-60.

35. Rampini SK, Bloemberg GV, Keller PM, Büchler AC, et al. Broad-range 16S rRNA gene polymerase chain reaction for diagnosis of culture-negative bacterial infections. 2011;53(12):1245-51. 